quiescent all the time, until the period alluded to, when from some cause or other it appears to have excited an attack of inflammation, which indirectly led to its expulsion. Perfect recovery followed the attack ; and, at the distance of several years, there has been no appearance of a tumour in the site which it formerly occupied, nor any trace of fulness of the liver, or other symptom of hepatic disease. Attacks of dyspepsia, however, recur from time to time; but the gastralgia has greatly abated both in severity and frequency.

\title{
ON CONICAL CORNEA.
}

By W. WHITE COOPER, Esq., F.R.C.S., Senior-Surgeon to the North London Eye Infirmary, and to the $\Lambda$ rtillery Company, etc.

[Concluded from last Number, $p$. 419.]

Mr. James Dixon, Surgeon to the Royal Ophthalmic Hospital, Moorfields, has, like myself, devoted much attention to the subject of Conical Cornea. On the publication of the first part of this paper, he, in the most handsome manner, placed at my disposal the result of his observations; and I cannot but feel, that any value, which my communication may possess, is greatly enhanced by the contribution of so accomplished an ophthalmic surgeon as Mr. Dixon. The following are his remarks :-

"Conical Cornea particularly engaged my attention about six or seven years ago. The rarity of the disease, and the consequently limited opportunities that had occurred for investigating it anatomically, and the contradictory theories on the subject, made me curious to learn more of this opprobrium medicina. I hoped to be able to determine for myself the real nature of the morbid change, but in vain; and, in the absence of any original researches into its true pathology, the notes $I$ now send can be only regarded as mémoires pour servir à l'histoire, rather than as history itself. I can at least offer you a complete table of the cases recorded at our hospital since its first establishment. You will observe that the disease is first mentioned in 1819 ; before that time it was probably classed with staphyloma.

"As regards the earliest notices of Conical Cornea, a curious mistake has been made by almost every writer on eye-diseases, from Wardrop downwards, in attributing to Leveillé the authorship of what he merely translated-namely, a note in Scarpa's Treatise on Diseases of the Eyes: but if the first edition of that work (Malattie degli Occhi, fo. Pavia, 1801), be referred to, the so-called 'note by Leveille' will be found entire at page 215. Our own countryman, Ware, however, had described the disease so early as 1795, in his 'Appendix and Notes annexed to the third edition of Remarks on the Ophthalmy, Psorophthalmy, and Purulent Eye' (p. 26), where he speaks of 'those rare cases, in which the cornea undergoes a change from its round figure, and assumes a conical or sugar-loaf shape'. For the cure of this, he says 'he had tried a variety of remedies-evacuation of the aqueous humour, followed by application of compresses ;' but adds, that ' the cornea always resumed its projecting figure. 
"It is uncertain whether the notorious John Taylor had really meen true Conical Cornea, when he designated a certain diseased condition of the part by the unmeaning term 'Ochlodes'. That the word was sonorous, and Greek, was quite sufficient to commend it to him whom Dr. Johnson cited as ' an example how far impudence could carry ignorance.'

“ Burgmann's often-quoted case is curious for its absurdity; and the best explanation of it was furnished by a non-professional critic, as related in Himly's 'Diseases and Malformations of the Human Eys' (Krankheiten und Missbildungen, etc., Berlin, 1843). 'The corneæ were black, as hard as horn, and hung down as far as the mouth. The learned have racked their brains to explain this phenomenon. Richter attributed it to expansion of the corneæ; Brandis, to the congestion produced by hanging; Blumenbach cites, in opposition to Brandis, a similar appearance in the eyes of a man whose head was cut off and then stuck on a pole; Heinlein thought that even in the latter case post-mortem expansion of the cornea might have occurred. The true theory of these Staphylomata is, doubtless, that of the Göttingen executioner- ' the crows made them.'

" CASES OF CONTCAL CORNEA REgIstered at THE ROYAL LONDON OPHTHALMIC BOSPITAL (FORMERLY INEIRMARY), MOORFIEIDS.

\begin{tabular}{|c|c|c|c|c|c|c|}
\hline Year. & Patients & $\begin{array}{c}\text { Cases of } \\
\text { Con. Cornez }\end{array}$ & & sar. & |Patients & $\begin{array}{c}\text { Cases of } \\
\text { Con. Comea }\end{array}$ \\
\hline 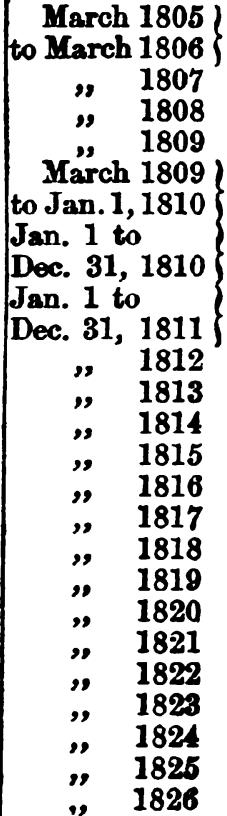 & $\begin{array}{r}600 \\
1526 \\
2126 \\
2357 \\
2179 \\
2907 \\
\\
2920 . \\
3085 \\
3392 \\
3016 \\
3445 \\
\mathbf{3 6 3 4} \\
\mathbf{8 4 7 0} \\
\mathbf{3 5 7 5} \\
\mathbf{3 7 0 1} \\
\mathbf{8 7 0 4} \\
\mathbf{3 3 8 3} \\
\mathbf{3 6 0 8} \\
\mathbf{8 5 2 3} \\
\mathbf{3 7 1 1} \\
\mathbf{4 0 7 8} \\
\mathbf{4 3 6 6}\end{array}$ & $\begin{array}{l}8 \\
7 \\
4 \\
4 \\
6 \\
8 \\
2 \\
4\end{array}$ & ", & $\begin{array}{l}1827 \\
1828 \\
1829 \\
1830 \\
1831 \\
1832 \\
1833 \\
1834 \\
1835 \\
1836 \\
1837 \\
1838 \\
1839 \\
1840 \\
1841 \\
1842 \\
1843 \\
1844 \\
1845 \\
1846 \\
1847 \\
1848 \\
1849\end{array}$ & \begin{tabular}{|r}
4955 \\
5478 \\
5266 \\
5429 \\
10550 \\
\\
10609 \\
\\
5154 \\
5016 \\
5586 \\
4874 \\
4891 \\
5355 \\
5521 \\
6086 \\
6572 \\
6874 \\
7005 \\
7010 \\
7672 \\
8382 \\
8418
\end{tabular} & \begin{tabular}{|c}
5 \\
3 \\
4 \\
6 \\
10 \\
6 \\
Report not \\
classified \\
3 \\
Report not \\
classified \\
2 \\
2 \\
10 \\
5 \\
7 \\
None \\
12 \\
4 \\
9 \\
5 \\
6 \\
2
\end{tabular} \\
\hline
\end{tabular}

I add the names of such patients in the annexed list, as came under my own care: 1844, I. John Cottrell, aged 34 ; II. Anne Child, 33 ; III. Catherine Richardson ; IV. Henry Burgess, 24 ; 1846, V. Samuel Luwis, 23 ; 1846, VI. Wilhelmina Jackson ; VII. Isabella Barnes, 27 ;

I am entirely of this opinion, W. W. C. 
VIII. Sarah Corsan, 81 ; IX. Maria Roeves ; 1848, X. Robert Moore, 28 ; XI. Emma Read, 22; XII. Jane Hammond, 18; XIII. Sarah Habberfield, 27 ; 1849, XIV. Maria Burr, 25.

"I have found a table on the following plan useful for registering, within a small space, the chief points of interest in cases of Conical Cornea.

\begin{tabular}{|c|c|c|c|c|c|c|c|c|c|c|c|c|}
\hline \multirow[t]{2}{*}{ Name Age } & \multirow[t]{2}{*}{ Occup. } & \multirow{2}{*}{$\begin{array}{l}\text { Right } \\
\text { ege. }\end{array}$} & \multirow{2}{*}{$\begin{array}{l}\text { Lef } \\
\text { eye. }\end{array}$} & \multicolumn{2}{|c|}{$\begin{array}{c}\text { Opacity at } \\
\text { Apex of Cone }\end{array}$} & \multirow{2}{*}{$\begin{array}{c}\text { Age when first } \\
\text { noticeal by } \\
\text { patient. }\end{array}$} & \multicolumn{2}{|c|}{$\begin{array}{c}\text { Reading focus } \\
\text { in inches. }\end{array}$} & \multicolumn{4}{|c|}{$\begin{array}{c}\text { Improvemeat } \\
\text { from }\end{array}$} \\
\hline & & & & Right | & Left. & & Righ: & Left. & gla & & ipert & \\
\hline $\begin{array}{l}1844 . \\
\text { J. C. } 34\end{array}$ & Paint. & Compl. & Partl. & 0 & 0 & 29 & 0 & 7 & $\begin{array}{c}\mathbf{R} . \\
\mathbf{0}\end{array}$ & L. & $\begin{array}{c}\text { R. } \\
7\end{array}$ & $\left|\begin{array}{l}L \\
12\end{array}\right|$ \\
\hline $\begin{array}{l}1848 . \\
\text { E. R. } 22\end{array}$ & Servt. & Compl. & Compl.| & 0 & Densel & & 2 & O & 0 & 0 & 6 & o \\
\hline
\end{tabular}

"Causes. The various opinions as to the changes which a cornea undergoes in becoming conical, may be classed under three heads:protrusion, from over-secretion of aqueous humour; central thickening; central thinning.

“The first opinion, advocated by Lyall and others, is altogether hypothetical, and is disproved by the fact, which you must have constantly noticed, that in even extreme cases of conical deformity, the plane of the iris is vertical. Any pressure strong enough to push the firm cornea forwards, would surely be sufficient to thrust the yielding iris backwards; and the concave form which the iris really assumes in true inflammatory dropsy of the anterior chamber, is, as far as my own experience goes, never accompanied by any corresponding prominence of the cornea.

“ No one, I believe, who has actually dissected a Conical Cornea, has found the centre thickened. Jæger, of Erlangen (not F. Jæger, the Vienna professor) has, on the contrary, described that part as being extremely thin ; and his description (in Schmidt's Thesis), short as it is, is the fullest I can meet with.

" The difficulty of assigning a constitutional cause to the disease must be very great, when we consider the widely different aspects of those who are the subjects of it. A greater contrast could not be found than between No. $X$ and No. XII in the foregoing list: the former, a pale, unhealthy-looking London workman ; the latter, a fresh-coloured, robust country girl.

"The statement, advanced by Sichel-that Conical Deformity of the Cornea is always preceded by a central ulcer-needs to be confirmed by careful observation : but I may quote one case which seems to support this view, and is otherwise remarkable as an instance of Conical Cornea at a very early age. Priscilla Saunders, aged four years, was brought to me April 9th, 1847, with an opacity at the centre of the left cornea, the result of a small ulcer which had cicatrized. The cornea was very slightly conical. On February 8th, 1849, she was brought again, the sight of this eye having become very defective. I found the small cicatrix in the same state as before, but the cornea had assumed a completely conical form. Had I now seen the case for the first time, I might have thought that the central opacity had been the result of 
friction upon the apex of the cone. The child saw perfectly with the right eye, but could not distinguish large lotters with the left, although the opacity hid only a portion of the pupil.

"On the other hand, in the case of Cottrell (No. I. supra), the corneal deformity was not preceded by any inflammation, and it commenced when the patient was of an age to notice and describe his symptoms. He had been fond of shooting, and always shot from the right shoulder, until he found himself becoming short-sighted with the right eje : he was then about twenty-nine, and the short-sightedness gradually increased, until he came to me with a cornea as conical as any I ever saw.

"As regards the Treatment of Conical Cornea, I have never found any of the astringent drops and lotions, recommended by ophthalmic writers, of any service whatever. Operative means I have always avoided. A metal plate with a small hole in it, or, what is better still, a transverse slit, fitted into a spectacle frame, has been the best mechanical contrivance I could find, and of more service than any form of concave glass. I have, however, met with two or three cases of conical deformity, seemingly uncomplicated with any other disease of the eye, in which the perforated plate and the concave glass were equally unavailing.

"The treatment I should feel least inclined to try, is that termed by its advocates 'the emeto-purgative plan,' which consists in giving the patient a scruple of sulphate of zinc, and two or three drachms of sulphate of magnesia, daily for the space of a year or more. It seems strange to give these substances together; for, if the patient is to be purged, why give him that which will cause the purgative to be vomited up? If the stomach, after a certain time, gets so accustomed to the sulphate of zinc as to retain it, the treatment becomes simply 'purgative', without the 'emeto'. How will the daily scruple of the sulphate of zinc affect the stomach, when it ceases to produce sickness? I cannot answer the question from my own experience; but I have seen a case where the system was followed, and at the end of twelve months the patient's corneæ were precisely in the same state as at first.

"London, May 2nd, 1850."

J. D."

TrEajMent. The various modes of treatment recommended for Conical Cornea are now to be considered.

Artificine Pupil. The first who proposed to assist vision in this disease, by extending the pupil to one side, was the late distinguished surgeon, Mr. Tyrrell. " "Within the last six years," says he, "I have succeeded in relieving such cases to a considerable extent by a plan so simple, that $1 \mathrm{am}$ surprised that it had not been previously tried. It consists in altering the position of the pupil, and removing it from beneath the centre of the cornen, or that part which has its figure most changed, to near the margin, where the least change has occurred; the error in refraction is consequently much lessened, and the vision becomes more perfect and the focus lengthened." Mr. Tyrrell states, that he had performed this operation seven or eight times with benefit, which, in two instances, was very marked. It is to be regretted, that a more particular history is not given of the cases. Three, I succeeded in tracing. Of these, one had recovered good vision, a second derived 
no ultimate benefit, while in the third the eye was lost by destructive inflammation. Thus, however encouraging the results might have at first appeared, the expectations, in two cases at least, were not destined to be realised. The experience of some authorities of eminence, with whom I have been in correspondence, is as follows. Dr. Butter, of Plymouth, states, that "we have tried to drag the pupil to one side of the centre, by making a small opening in the cornea and introducing a barbed hook, but seldom I think, with very marked success." Mr. Barton, of Didsbury, has treated this disease by various operations, viz.: " evacuating the aqueous humour frequently, by puncturing the cornea with a necdle, or cataract knife ; extracting the lens, enlarging the pupil at the lower margin by cutting off a piece of the iris, or strangulating it in the incision, according to the circumstances which have presented during the operation. The benefit, however, resulting from any of these operations, has never been commensurate with the risk, and many cases were rendered worse by the treatment." Mr. Neill, of Liverpool, has met with better success. "You ask me," says he, "of my means of cure. There were three cases cured by me: in one, after pursuing the system of puncturing the cornea every two or three weeks, evacuating the aqueous humour, and using pressure, the eye became flattened and vision was useful ; the other two cases had each the cornea punctured and a fibre of the iris removed, an oblong pupil being thus formed at the outer and lower edge of the cornea, where it was tolerably flat, and in both these cases very good sight was gained. This practice I shall hereafter pursue, when two eyes are similarly affected, or when one is lost and Conical Cornea exists in the other. Such a case $I$ have now under my care. The hostess of a large hotel, in opening a sodawater bottle, which burst in her hand, had one eye dreadfully torn. The other eye has a Conical Cornea. When the inflammation of the wounded eye is sufficiently removed, I will proceed to alter the form of the pupil in the other, and have no doubt that the sight, in this case also, will be rendered useful." Mr. Wilde, in his admirable Report on the Progress of Ophthalmic Surgery,' gives an interesting case, illustrated by a woodcut. "The only case," he says, " in which we have ever produced permanent benefit, was one in which we performed an artificial pupil, as recommended by the late Mr. Tyrrell. In this instance, the lady was scarcely able to find her way through the streets. She had consulted the principal oculists in these countries, and had undergone several courses of treatment. She had been for a long time under the care of the late Mr. Wardrop, who tapped the cornea several times. In the summer of 1842, assisted by Mr. Cusack, we performed an artificial pupil in her right eye-not as recommended by Mr. Tyrrell, by cutting out a portion of the iris, but by drawing its pupillary margin through an incision in the cornea, made close to its insertion with the sclerotic externally. This lady now reads very well by holding the book towards the right side." The late Mr. Walker, of Manchester, informed me that " in one case in which both eyes were affected to an extreme degree, I first performed the operation (as practised by Middlemore and Tyrrell) of displacing the pupil and afterwards extracting the

1 Dublin Quarterly Journal of Medicine, vol. xxxiv, p. 491. 
lens. That operation answered beautifully in one eje; but the other eye was attacked with violent inflammation, and was destroyed. I should not hesitate again to perform that operation in a suitable case. All the cases I have since seen, have been such as have only hud one eye extremely affected, the other being only slightly so ; and consequently I hare not felt justified in recommending an operation of that magnitude and importance. The mere displacement of the pupil I do not think much of." Mr. Walker was so good as to favour me with the particulars of the case alluded to, which possesses considerable interest.

CA8E. Joshua B., æt. 47. His sight had begun to fail after an attack of inflammation, and during seven years had gradually become worse. In August 1841, he placed himself under the care of Mr. Walker. $\mathrm{He}$ could find his way about, and read moderate sized type at a distance of two inches; with the right eye, when the lids were almost closed, he could read at a greater distance, but not so with the left. A luminous body appeared to be multiplied ten or eleven times, but no chromatic aberration was observed. This multiplication of images was confined to luminous objects, and these appeared single when the eyelids were nearly closed; the point of the cone in each eye was opaque-the opacity being densest in the left. Neither concave glasses nor a pinhole improved vision. On the 25th September, 1841, Mr. Walker punctured the cornea of the left eye and removed a portion of the iris, extending the pupil to the inferior margin of the comea; very little irritation followed, but the amendment of vision was only such as to increase the reading distance to three inches. Mr. Walker now removed the lens. Some trouble was subsequently experienced from opaque capsule blocking up the pupil, but the ultimate result was, that the patient nearly recovered the perfect sight of the eye. He could read small print at the ordinary distance, and see surrounding objects a great way off; moreover, the conicity of the cornea was almost entirely romoved. Similar proceedings were adopted towards the right eye, but there followed destructive inflammation, and the eye was lost.

Dr.J.C. Hall tells me that he has " seen no good from operations, with the exception of frequently evacuating the aqueous humour, not even from dislocating the pupil"; and other correspondents have expressed themselves as adverse to the operation. Dr. Billett, of Taunton, says, "I once made an artificial pupil through the sclerotic, which enabled the patient to see a strong light, which was all that he asked for." This case, however, could not have been one of Conical Cornea, in the strict sense of the term; for in such cases the perception of light is not extinguished.

My own experience of the value of an artificial pupil extends to three cases, which I will proceed to relate. It will be seen that in one there was improvement; in the second also improvement, but very slight; whilst in the third neither the simple extension of the pupil, nor the combination with it of removal of the lens, assisted the vision of the patient.

Case i. Artiftcial Popir. Arabella Thomas, aged 19, a delicate looking girl, applied to me May 5th, 1848 . For many years her vision had been imperfect, especially with the left eye, which had in. deed become almost useless, as she could only discern objects by hold- 
ing them quite close to the outer side of the organ. The sight of the right eye, though very obscure, was better than that of the left. Lumi. nous objects were multiplied and surrounded by belts and rays. The left cornea was very conical, the apex of the cone presenting a dimple surrounded by a nebulous haze; a magnifying glass displayed several irregularities and facets, especially on the upper part, near the apex. The right eye presented the phenomena of the disease in a less degree. On dilating the pupil with atropine, and causing her to look through a pin-hole, it was found that when the aperture was opposite to the lower and outer third of the expended pupil, a very decided improvement in her sight took place.' She could then read with facility at five inches, whereas, before, she could only make out letters at two inches distance. It was then decided to extend the pupil at the point mentioned. On the 28th of May, an incision was made with a curved Scott's knife, just beneath the transverse diameter of the cornes at the outer side, and a fibre from the margin of the pupil, being drawn out with fine forceps, was snipped off. There was a little hæmorrhage into the anterior chamber, which speedily subsided under the influence of cold.

No ill consequences followed the operation; and, after the lapse of three months, the patient could read and work at the distance of four inches from that eye, and could discern features tolerably distinctly at four feet.

Case II. Armficiar Poprr. Jane Robertson, aged 27, of delicate and poverty-stricken appearance, came under my notice January 11, 1848. She was a milliner, but for nine months she had been unable to work from imperfection in her vision. About eighteen months prior to her application, she first perceived a difficulty in distinguishing objects clearly with the right eye when looking directly at them, but by turning her head a little on one side they appeared clearer; at the same time she was much annoyed with muscro volitantes, and occasionally felt an uneasiness and fulness in the eye. The sight gradually became worse, and in about six months the left eye was in like manner affected. The difficulty in discerning objects increased, until she was obliged to hold her work quite close to her eyes and to look at it obliquely. Being dependent on her needle for subsistence, she was compelled to work many hours each day, until at length she could no longer see, and was obliged to yield to her rapidly increasing blindness.

The unmistakeable sparkle of the ejes at once proclaimed the nature of the case ; for, in each, Conical Cornea was well marked. The apex of the right cone was somewhat more opaque than that of the left, and each cone presented a dimpled point. She could only discern capital type by holding it at about an inch and a half from the eyes, but through a pinhole, could see it at three inches. On dilating the pupils with atropine, there was some improvement, which decided me to attempt relief by an artificial pupil. On the 20th January, I operated on the right eye, making an incision at the outer margin of the cornea. A considerable gush of aqueous humour took place, the cone collapsed, hecoming some-

1 Secale cornutum, used as a snuff, has been said to cause contraction of the pupil. I have tried it in many instances of dilatation of the pupils, natural and artificial, but have not observed the effect in question. 
what corrugated, and the iris fell forward. With a pair of fine forceps; the margin of the pupil was drawn out, and a few fibres snipped off. On the following day the cornea was moderately filled, and there was a decided improvement; but the reduction of the size of the cone being considered, little stress was laid on the amendment. The recovery was rapid, and the vision was certainly somewhat improved, but not sufficiently so to enable her to work, and I did not therefore think it desirable to adopt any further operative measures.

Case iif. Artificial Pupir and Destruction of the Lens. Anne Reeder, aged 17, was sent to me from the country, in September 1847. Her head was unusually long in the antero-posterior direction, as if she had suffered from hydrocephalus. The vision of her right eye had been imperfect from early youth, and had gradually become useless; the vision of the left eye was alsc imperfect; the eyes were remarkably deeply set, and the palpebral fissure small; the conical form of the right cornea was strongly marked, that of the left decided, but less prominent than thie right; the apices of both were slightly turbid; the surface of each was smooth, and neither halos nor multiplication of images had been perceived; vision was not improved by a pin-hole, nor by any kind of lens.

On the 22nd of October I made a puncture at the inferior third of the outer side of the right cornea, and drawing out a small portion of the margin of the pupil, snipped it off. There was considerable hæmorrhage into the anterior chamber, but it yielded to the application of cold. So rapid was her recovery, that she left the Eye Infirmary on the 29th of October, with a very good artificial pupil, but without any amendment in her sight. She came in again on the 8th November, and the recovery from the previous operation was so complete, that I determined to try the effect of destroying the lens, as recommended by Mr. Walker and others. On the 10 th November the lens was destroyed with a cutting needle; no unpleasant symptoms followed, and the fragments became in due time absorbed, but there was no material amendment in her sight, either then or in June 1848; since which time I have not seen her.

If artificial pupil be contemplated, it should be ascertained whether dilatation of the pupil improves the sight, and whether there is any point through which the vision is better than elsewhere. When irregularities of the surface exist, some spots are freer than others, and here the cornea is best adapted for the transmission of visual rays.

Removal of the Crystalline Lens. In reference to this operation, it must be borne in mind, that perfect vision is due to the combination of accuracy of form of the cornea and crystalline, with that beautiful arrangement of the fibres and layers of the lens, by which the rays undergo gradual refraction in their course through it, and are united in foci exactly upon the retina. The imperfection of vision in Conical Cornea, is caused less by alteration in the actual refractive power in the eye, than by the vicious manner in which refraction is performed; the alteration in figure of the cornea prevents the formation of foci at the proper points, and causes unbounded confusion in the images depicted on the sentient membrane. Though, by removal of the lens, the refraction within the eye is lessened, the harmonious bending of the rays 
accomplished by the crystalline, cannot be attained, nor can the condition necessary for the formation of images be recovered. It is justly remarked by Dr. Pickford, in his able treatise, that the sphericity of the cornea, so to speak, is totally lost, saving so much of its obtuse apex as approximates to the form of the healthy cornea; and that we have no longer to treat an ellipsoid of revolution, but a plane surface, - the slant sides of the cone. Thus the alteration in the conditions for refraction anterior to the lens, is not of a nature to admit of compensation by the removal of that body.

Destruction of the crystalline lens was proposed with great confidence by Sir W. Adams, as a cure for Conical Cornea. The cases which he has related are highly flattering to his skill; but, independently of the optical objections, and the formidable character of the proceeding, it has been strongly condemned by high authorities. The late Mr. Tyrrell said, "It was thought that the removal of the crystalline lens, by getting rid of that convex and highly refractive body, would afford better vision in such cases; but the practice has not in the least degree supported the theory; for it does no good." Mr. Lawrence "would not think of proposing any such operation, unless the affection had gone so far as to render the eye useless, and he would then expect no good from it. The proceeding has not been employed with advantage in any instance." Dr. Pickford is of opinion, that the removal of the lens is uncalled for, injudicious, and indefensible.

That the removal of the lens is sometin 's of service, is proved by the following evidence; but my impression is, that such cases form the exception, not the rule.

In 1847, Dr. Butter, of Plymouth, wrote to me as follows: "I couched a woman, thirty years since, who had cataracts and Conical Cornea. She has seen well ever since, with or without flat (?) glasses." In a similar manner I was informed by Dr. Robertson, of Edinburgh, "I have operated in one case of cataract, conjoined with a highly Conical Cornea. The apex was irregular on its surface and slightly opaque. The patient could afterwards read the smallest print, the book being held somewhat to the side, but in looking at any object held directly in a line with the centre of the cornea, the centre of the object was scarcely visible. The glasses usually required after the removal of the lens, were, as was naturally anticipated, injurious, the conical form of the cornea compensating for the loss of the lens. The operation performed was that of reclination." When speaking of artificial pupil, I have mentioned a case related to me by the late Mr. Walker, of Manchester, in which he combined extraction of the lens with artificial pupil with success; but he particularly mentions, that the conicity of the cornea was almost entirely removed by the operation,-Doubtless by the section of the cornea. ${ }^{2}$

1 The figure of the healthy cornea is an ellipooid of revolution about the major axis, through which the curvature of all its sections is equal, and it presents in every direction an arc of $96^{\circ} 55^{\prime} 20^{\prime \prime}$.

2 Mr. Estlin of Bristol thus writes: "One croe occurred to me, where the lens of an eye, with Conical Cornea, was wounded by a needle, which ruptured the capsule and produced a cataract, which became absorbed by the effect of the accident which occasioned it. The loss of the lens improved the power of seeing." 
Though doubting the effercy of the proceeding, I considered it $m$ y duty, after the foregoing statements, to give the patient the benefit of the chance in two instances, and am bound to state that the result was not sufficiently encouraging to induce me to recommend the operation; unless, of course, cataract should chance to be combined with Conical Cornea, in which case it would be perfectly justifiable.

Case Iv. Destruction of the Lens. Luke Gibson, carpet-weaver, æt. 23, came under my care in March 184\%. Both eyes presented Conical Cornea, the right being more prominent than the left. The usual symptoms were present, and he found so much inconvenience, that he was eager for any means which afforded a chance of relief. All milder measures having failed, and there appearing to be some cloudiness in the right lens, I determined to try the effect of removing that body. The anterior operation for solution was therefore performed with a broad needle, on the 26th April. On introducing the needle, there was a considerable gush of aqueous humour, and the cone became flaccid. After completing the operation, I availed myself of the opportunity of examining the collapsed cornea, and satisfied myself that, near the apex, it was scarcely thicker than silver paper. Absorption proceeded satisfactorily, but it became necessary to repeat the operation on the 27 th July, to remove some fragments of capsule which obstructed the pupil. On the 26th August the aperture was clear, but I was sorry to find that little, if any benefit, had been gained, nor were glasses of more use than before the operation. The rapidity with which the aqueous humour is secreted, was well shown in this case, for the cornea was plump and distended twenty-eight hours after the operation.

The second case, that of Anne Reeder, has been already related.

Rexoval of Segments of the Cornea. One case only, in which this step has been adopted, has fallen under my notice. It was communicated to me by Mr. Maling, of Sunniside, as follows: "I discharged the aqueous humour by making a section of the lower half of the cornea, and cut away a small portion of it, with a view of diminishing the anterior chamber; but the result did not answer my expectations, although the patient was certainly less myopic. The apex of the cone, after the operation, inclined downwards. I wished to operate in a similar manner on the upper portion of the cornea, but my patient would not submit."

By removing the apex of the cone somewhat to one side, especially the inner, and by combining with this treatment, the use of a fissured diaphragm, with or without a lens, benefit may probably be derived.

The Bulletino delle Scienze Médiche, of Bologna, for December 1838, contains the particulars of a case of Conical Cornea, treated in an unusual manner by an Italian surgeon, M. Fario. With a double-edged cataract knife, he made an incision at the outer side of the cornea, and a second, meeting the first at the point, in the form of the letter $V$ reversed. The flap was cut off with scissors. There resulted a gap, through which the aqueous humour continually drained. The lids were closed with sticking plaster, and the patient kept in bed in a dark room for eight days, no other drcssing being applied to the eje. At the expiration of that time, the lids were opened, when the breach in the cornea was found closed, and the cornea itself a little flattened. The same 
operation was repeated at the lower part of the cornea vith a similar result, but the flow of the aqueous humour continued longer this time, and the iris became entangled in the wonnd, but withdrew under the infuence of belladonna. A third excision was performed at the upper and inner part of the comea; and it is stated that the eye became flattened, and the patient cured.

The main objection to such a proceeding as that described, is the great risk of prolapse of the iris. It occurred in the present instance, and although the membrane is said to have retracted, such an event is by no means to be expected after it has been prolapsed eight or nine days; belladonna would then have but little effect in causing its retraction. Another objection is, the leucomata that would be produced by the cicatrices of the wounds. The new material formed to fill up the gaps in the cornea being fibrous instead of lamellated, and opaque instead of translucent, would leave permanent cicatrices of such a magnitude as would be unsightly, and obstructive to vision.

Puncturnig the Cornes. This, as might bo expected, has been resorted to in a great number of instances, but has failed to afford relief. I know of no more marked illustration of the rapidity with which the aqueous humour is secreted, than is presented under such circumstances; on the needle being introduced, the fluid spirts out freely, and the cone collapses. If the eye be examined about twenty-six hours afterwards, the cone will usually be found plump and distended : when about twothirds filled, there is often marked improvement in the sight, but the hopes thus raised are dispelled in a few hours. Mr. Evans, of Belper, says, "I have treated about a dozen cases of Conical Cornea, I am sorry to say, without materially benefiting any of them. The treatment of my early cases consisted in evacuating the aqueous humour, in one case more than ten times, astringent lotions, etc. Latterly, I have given up all local remedies as being utterly useless in my hands, and confined the treatment to the improvement of the general health." Not more encouraging is the report of $\mathrm{Mr}$. Soden, formerly of Bath. "In the course of thirty five years that I have been connected with the Bath Eye Infirmary, I think that I have not seen more than fourteen or fifteen cases of Conical Cornea. In two cases, I tried frequent evacuation of the aqueous humour, in the hope that the cornea might be somewhat flattened by the anterior chamber being emptied; but no advantage ensued, although in one instance I repeated the operation about thirty times, at intervals of two or three days. No injury, however, resulted from this treatment." I might multiply such accounts, but these examples are sufficiently confirmed, as they are most fully, by my own experience ; for though evacuation of the aqueous humour is of service when combined with fluid pressure, it is absolutely useless by itself.

Pressure. M. Desmarres thus writes: "Some have tried puncture of the cornea to evacuate the aqueous humour; if, with this, they had joined a compression, methodical, immediate and long-continued, as we daily use with opaque staphyloma, and as we have practised with great advantage in two cases of transparent staphyloma, such means would, perhaps, have been attended with the best results. ${ }^{1}$ Puncture of the cornea, followed by direct compression, appears to me the best means

\footnotetext{
1 Jessyarres, L. $\Lambda$. Traité Théorique et Pratique des Maladies des Yeux.
} 
known for the treatment of this disease, but the compression should be light, exactly made, and long continued." The correct principle is embodied in these views of M. Desmarres. Strong pressure by a solid body is injurious. It is support, rather than actual compression, which is needed. The thin and weakened cornea, unable to resist the pressure from behind, has been projected into a cone, and is incapable of recovering itself unless relieved from that pressure. Evacuation of the aqueous humour affords merely temporary relief, for the membrane is speedily again distended. John Hunter thus wrote: "We find very different effects from the same quantity of pressure ; for when from without, pressure rather stimulates than irritates, it shall give strength, and produce an increase of thickening; but when from within, the same quantity of pressure will produce waste, for the first effect of pressure from without, is the disposition to thicken, which is rather an operation of strength; but if it exceeds the stimulus of thickening, then the pressure becomes an irritator, and the power appears to give way to it, and absorption of the parts pressed takes place." It may be doubted whether this doctrine is altogether correct; for, as pointed out by Professor Paget, the results of pressure, whether from within or from without, appear to depend on its constancy or occasional application. In Conical Cornea, the pressure should be constant, but not limited to the apex of the $\operatorname{con} \theta$, or it will excite irritation; it should be so managed as to afford firm support to the whole cornea, thus counteracting the force of the muscles of the globe, removing the tension from the weakened membrane, and placing it in the most favourable condition for restoration to its natural thickness and figure.

Fluid pressure alone can perform this satisfactorily, for if this be properly applied, every part is equally supported, and the support is maintained under all circumstances, movements, and positions. I endeavoured to carry out these principles in the following manner. An apparatus was constructed, consisting of an air-cushion of fine membrane, fitted to the orbit and acted on by a spring which passed half round the head, the point of counter-pressure being the occiput. The spring was of just sufficient strength to cause as much pressure on the eye as could be borne without inconvenience, and it was supplied with an adjustment to increase or diminish the force. Anterior support being thus provided, the pressure from behind the cornea was removed by letting out the aqueous humour. Immediately on its ceasing to flow, the apparatus was applied. Could the air-cushion have been made impervious to moisture, and perfectly air-tight, the improvement which took place in one case, after three weeks' trial, leads me to believe that much benefit would have been derived, but, unfortunately, the cushion invariably collapsed after a few days' wear. Vulcanized india-rubber, or some form of gutta percha, may, perhaps, answer better, but no description of animal membrane is adapted for the purpose. I ascertained, however, that the pad could be worn immediately after the cornea had been punctured, without exciting the least pain or irritation. If a perfect cushion can be obtained, its use should be persevered in for at least two months, the cornea being punctured from time to time. With this treatment, careful attention should be paid to the general health, strength and tone being imparted

1 Hurter's Works. Edited by James F. Palmer. London : 1837. Vol. iii, p. 466. 
if needed, and congestion abated if it appear to exist. The various preparations of iron with aloes and myrrh, and the carbonate of manganese (of which I can speak favourably), are indicated in the first of these conditions. Counter-irritation by blisters and rubefacient liniments, is best calculated to remove the second.

Emeto-Purgative Treatment. This practice was introduced by Dr. Pickford, and advocated by him in a work of remarkable ability. 'The principles which have guided him are thus laid down. "I believe Conical Cornea to depend upon some disturbance in the functions of the great sympathetic, spinal nerves, and par vagum, producing, through the medium of the lenticular ganglia and fifth pair of nerves, faulty action of the nutrient capillaries and absorbent vessels of the cornea itself. Emetics and purgatives, by the powerful influence which they induce upon the gastric associate and consensual nerves, restore the healthy functions of the weakened nutrient and absorbent vessels, the result of which is a slow but progressive retraction of the diseased corneal growth, and a consequent restoration of vision." The medicines recommended, are a scruple of sulphate of zinc combined with half an ounce of sulphate of magnesia, to be taken every morning, or less frequently according to circumstances. Besides the cases recorded in the work, I am indebted to Dr. Pickford for the results of his further experience to 1848. "Since the publication of my paper on Conical Cornea, I have had many opportunities of treating the disease. The result, so far as the treatment has gone, has been most satisfactory, but I shall not attempt to conceal the fact, that patients become exceedingly tired of so disagreeable and so lengthened a remedy, and are disposed after a time to intermit it. When this has been the case, I have invariably observed an increased prolongation of the corneal cone, or an increased opacity of its apex. To say the least of it, my remedy has the power, when taken ever so irregularly, of keeping the disease in check, or of arresting it altogether. The,late Mr. John Scott told me that he had successfully adopted my plan of treatment. In no instance have any ill effects followed the lengthened use of the emetics; on the contrary, the general health and strength have invariably improved. I have now a young woman under treatment, in whom $I$ tried the nauseating effect of the remedy merely, short of vomiting; but under this modification the disease increased, and at her earnest solicitation the full effect of the medicine was again resorted to."

In two instances in which I attempted to give the emeto-purgative treatment a fair trial, the patients were of opinion that the remedy was worse than the disease, and neither argument nor persuasion could in. duce them to follow it up for a sufficient length of time to enable me to judge of its real merits. It will be seen that Mr. Dixon has formed a strong opinion on the subject.

LOCAL APplications. 9 These comprise two classes, simple astrin-

1 Pickrord, J., M.D. On Conical Cornea. Dublin : 1844.

I Just before going to press, an opportunity was afforded me of perusing the paper by $M$. Sichel, in the second supplement of the $A$ nxales $d '$ Oculistique. M. Sichel is of opinion, that Conical Cornea is invariably the result of ulceration, which weatens the cornea ; and in proof of this, he asserts that a small cicatrix is comerantly to be found at the apex of the cone. This is at variance with the experience of 
gents and escharotics. With very rare exceptions, little or no benefit has resulted from such remedies; every known combination soems to have been tried and to have failed. The most favourable reports are those of Mr. Ware, Mr. Gibson, Mr. Lyall, and Mr. Gervis. Mr. Ware states: "In some instances I have punctured the cornea and evacuated the aqueous humour, after which, by the application of thick compresses to the outside of the eyelids, I have endeavoured to counteract the morbid propensity; but, when this humour has been regenerated, which usually takes place in a short space of time, the cornea has always resumed its projecting figure. The greatest relief I have hitherto given, has been by the application of a few drops of strong infusion of tobacco; by a perseverance in the use of this remedy, three or four times every day, the conical appearance of the eye has in a few instances been diminished and the patient's sight greatly mended."1 Mr. Gibson, of Manchester, used collyria of alum and oak in four cases, and in these no increase took place; one patient, indeed, thought his vision was improved. As, however, the disease often comes to a standstill after having arrived at a certain point, but little stress can be laid upon the influence of the treatment in these cases.

A curious case is related by Mr. Lyall. A young woman suffering from Conical Cornea in both eyes, was suddenly attacked with severe headache, great pain in the left eye, and a copious discharge of scalding tears. The apex of the cone became quite opaque in two days; shortly after, Mr. Lyall applied nitrate of silver, when violent action was excited and the opacity partly disappeared. Mr. Lyall then punctured the cornea several times, and used strong astringent collyria, the result being diminution in the size of the cone and decrease in the opacity; but (it is important to remark), the vision was not improved.

Mr. Gervis, of Tiverton, has been fortunate in his management of this disease. A young woman at 25 , had suffered for two years from Conical Cornea in the right eye, and has been under medical treatment for a year and a half. Mercury had been exhibited freely, and had produced much debility. The plan adopted by Mr. Gervis was continued counter-irritation by means of blisters, full doses of carbonate of iron for two months, compound galbanum pill, and liberal diet. The cornea was several times punctured, and the cone swept with nitrate of silver thrice a week. Some opacity of the projection resulted,

Mr. Dalrymple, Mr. Dixon, and myself. We have each repeatedly seen instances of Conical Cornea, in which no opacity whatever existed.

The treatment recommended by M. Sichel, to give solidity to the weakened membrane, is as follows. The projection is to be touched once or twice a day with vinum opii, and the lids being immediately closed, are to be bathed with cold water. Suberequently there may be used with this, an ointment of red or white precipitate, ten or twenty grammes to two grammes of lard. Every two or three days, if the eye will bear it, a pencil of nitrate of silver is to be swept lightly over the opacity, expecially the summit of the cone, but not over the sides. The surface having been wiped with fine rag, a little cerate is to be applied. These cauterizations may be continued during one or two months, being suspended from time to time, if necesary. Should the progress of cure be slow, and the cone large, puncturing and compresesion may be employed, the one alternating with the other, and with the canterization. Measures for the improvement of the general health should be combined with this treatment. We are not aware that this practice has found favour on this side of the Channel, nor can we speak from experience of its efficacy.

1 W ARE, Jas. Chirurgical Observations Relative to the Eye, vol. ii, p. 77. 1805. 
and the unguentum hydrangyri nitrico-oxydi was applied daily to the eyelid. At the expiration of three months, the cornea had recovered its natural shape, and the sight was completely restored. In another instance similar treatment, in combination with emeto-purgatives, rendered much service. To the judicious combination of general treatment, with local remedies, must the happy result of these cases be ascribed, rather than to the predominating influence of any application in particular.

It occasionally happens that the apex of the cone will become opaque in cases of old standing, from some slight exciting cause quite independent of friction of the lid. Such attacks are amenable to treatment, and it is important that the opacity should be speedily removed. The following case, for which I am indebted to my friend Mr. Dalrymple, is a good illustration of these attacks, and the means by which they are to be arrested.

Case v. Opacity removed by Lothons of Acetate of Zinc, and Iron INTERnally. A lady, aged 35, consulted Mr. Dalrymple on 18th March, 1850. She had suffered from Conical Cornea for twelve or fifteen years, and some years ago consulted many eminent men without relief. Until bately she had been able to read with either eye, at two inches focal distance. The cone was strongly developed in the right eye, but perfectly transparent. The left cornea was still more sharply conical, and until within three weeks of the above date, was also clear. She supposes that she caught cold during the recent severe weather, for, without any redness of the eye, opacity supervened, invading the apex of the cone of the left eye; she had been in the habit of reading over much, her health was feeble, and circulation languid. A doubtful prognosis was given as to the probability of the opacity becoming absorbed, but she was recommended to take 10 drops of the tinct. ferri sesquichl. thrice a day, with aloes and myrrh, and to frequently drop into the eye a collyrium, containing one grain of acetate of zinc to an ounce of distilled water. Twelve days afterwards, she reported by letter, that the opacity had disappeared, and that she had begun to see as well as before the attack.

Nitrate of SiLver and TrNeture of Iodine to the Eyeuids. Mr. Smith, of Southam, speaks favourably of this description of counterirritation: "In two cases," says he, "I have given considerable satisfaction by the application of argenti nitras, on the external surface of the upper lids, and so keeping up a little scaly eruption or desquamation of the skin : one girl found great relief, having suffered from the complaint for two years." In two cases in which the disease was clearly connected with struma, and was accompanied with intolerance of light, I made trial of the daily application of the tincture of iodine to the lids with decided benefit to the photophobia. It may be remarked, that this remedy is of great value in ordinary strumous ophthalmia.

HrDROCraNic Acrd VAPOUR. To this I gave a full trial in several cases. The only effect was diminution in the opacity when such existed.

Electro-MaGetrsy. No visible change followed the use of this agent, though persevered in for several weeks.

Optical Apparatos. The ingenuity of opticians has been severely taxed, to endeavour to remedy the defective sight in Conical Cornea, by artificial means. It being found that in some cases vision was improved when looking through a pin-hole, various forms of apparatus have been 
constructed on this principle. Mr. Travers has recommended a frame of black wood, half or a quarter of an inch in depth, having a small aperture; opake diaphragms have been varied in form, and pierced with a fine slit in the centre, or removed somewhat to the side. In several instances, I have seen decided benefit from the use of such an apparatus, either singly or combined with lenses. The diaphragm should be a thin plate of horn or metal, fixed in a spectacle frame. No precise rule can be laid down as to the size, direction, or position of the aperture, for there are scarcely two cases precisely alike, and each requires to be carefully tested with apertures of various forms and dimensions. Such an instrument improves vision by limiting the number of rays impinging on the cornea, and thereby lessening the confusion of foci in the interior of the eye. When neither the diaphragm nor a lens separately succeed, the two together will sometimes prove effectual. The number 11 double concave, fixed to a diaphragm pierced with a narrow slit, will cocasionally render valuable assistance, but the power of the lens and the size of the slit are quite matters of experiment. In one instance; and only one within my knowledge, did a double convex glass answer better than the concave; on its being fixed to the diaphragm the patient and optician were alike surprised at the great improvement which it caused in a very bad case.'

Sir John Herschell has suggested the adaptation to the eye of a lens of nearly the same refractive power as it, and having the surface, next the eye, an exact intaglio fac simile of the irregular cornea. Should, says he, " any very bad cases of irregular cornea be found, it is worthy of consideration whether at least a temporary distinct vision could not be procured, by applying in contact with the surface of the eye, some transparent animal jelly contained in a spherical capsule of glass; or whether an actual mould of the cornea might not be taken and impressed on some transparent medium. The operation would be delicate, but certainly less so than that of cutting open a living eye and taking out its contents." This proceeding seems to me more simple in theory, than easy of practice.

Lenses ground to different forms have been tried with more or less success. Dr. Hull states that in a very bad case, much benefit resulted from the use of an instrument, formed of two lenses, with an adjustment; the lens nearest the eye being small and doubly concave, the other large and convex.

Could but the rays of light (as Dr. Pickford justly remarks), reach the lens, with accustomed regularity of convergence, all would be well; a deep double concave glass, by occasioning a prior divergence, would remedy the defect of rision; but could they do this, one of the very peculiarities of the disease itself would vanish and cease to exist. Besides this difficulty, there is another; namely, that though a correct shaped lens might be obtained, it would not answer unless placed at the exact distance from the eye that is required; and always retain the same relative position. Should a person be desirous of really deriving benefit from lenses he might proceed thus : First, let him try a plano-

1 Mr. Hawes, 79, Leadenhall.street, has had much experience in the manufacture of diaphragms, etc., for Conical Cornea.

'Article, "Light", Encyclopadia Metropolitana. 
convex lens, the concarity being about equal to the convexity of the cornee, taking care that the curve is as nearly parallel to the curve of the cornea as possible, when placed at the most suitable distance from the eje. It is obvious that every distance has its peculiar curvethe greater the distance, the less the curvature, as it is in concentric circles. If that form should not be satisfactory, he might then try, instead of a plano-convex, a convexo-concave, and afterwards a double concave, only taking care that the two concaves partook of the form of the curve of the cornes; that is, both the inner and the outer curves should be similar in form to that of the cornea, but of less currature; or, in. other words, instead of being portions of spheres as is usual in lenses, the curres should be portions of parabolas or hyperbolas as the case may be, varying the amount according to the distance of the lens from the eye, and according to the form of the Conical Cornea.

It will be seen by this survey of the various modes of treatment, that there is not one which offers more than prospects of success. Patients have rarely determination sufficient to carry them through the discomforts of the emeto-purgative course; and although the operations of artificial pupil and destruction of the lens have each their adrocates, the amount of success which appears on impartial examination is not sufficient to counterbalance the formidable nature of either proceeding, or to justify their employment unless as a dernier ressort. On the whole; I place most trust in the combination of puncturing with fluid pressure, judicious attention being at the same time paid to the general health, It has at least the rucommendation of simplicity, and if unsuccessful, the pationt is not left in a worse condition than before. Prior to any operntive measures, all the points of the case should be fully considered. and it is proper to ascertain whether the vision be assisted by the limited apertire or by the use of belladonna. A card blackened with ink and pienced with large pin, makes an excellent experimental ditphragm ; and the moat elegant preparation for dilating the pupil, is a solution of from two to four grains of the neutral sulphate of atropine in an ounce of distilled wator.

19, Barkeloy Bquare, March 1850.

Norz. To the following gentlemen, my cordial thanks are rendered for the valuable information which has formed the groundwork of this paper. Dr. F. Jeeger, Vienna ; M. Sichel, Paris; Sir John Richardson. Mr. Dalijuple ; Mr. James Dixon ; Mr. Rainald Martin ; Sir John Fife ; Mr. B. L. Enith, Bouthm ; Dr. Butter, Plymouth; Dr. Billet, Taunton: Professor Andren Anderson, Glasgon; Dr. Mackenzie, Glasgow: Dr. Cadenhead, Aberdeen; Dr. Keith, Aberdeen; Dr. Pickford, Brighton; Dr. J. C. Hall, Eas Retford ; Mr. Squaire, Plymouth ; Mr. W. Walker; Ddinburgh ; Mr. Gervis, Tiverton ; Mr. Isbell, Stonehouse ; Mr. Sodén, Sunbary ; Mr. Evans, Belper; Mr. Mould, Plymouth; Mr. Neill, Liverpool ; Mr. Estlin, Bristol ; Mr. Barnes, Exeter ; Mr. Delagarde, Exeter; Mr. Cleobury, Oxford ; Mr. Maling, Sunniside; Mr. Braithwaite, Leods ; Mr. Greenhow, Newcastle ; Mr. Barton, Didbury ; Dr. J. A. Robertson, Edinburgh ; Mr. Percival, Ist Life Guards ; Mr. Ryland, Birmingham; and Mr. W. R. Wilde, Dublin. 